\title{
NEW COUNCILLORS FOR 1983
}

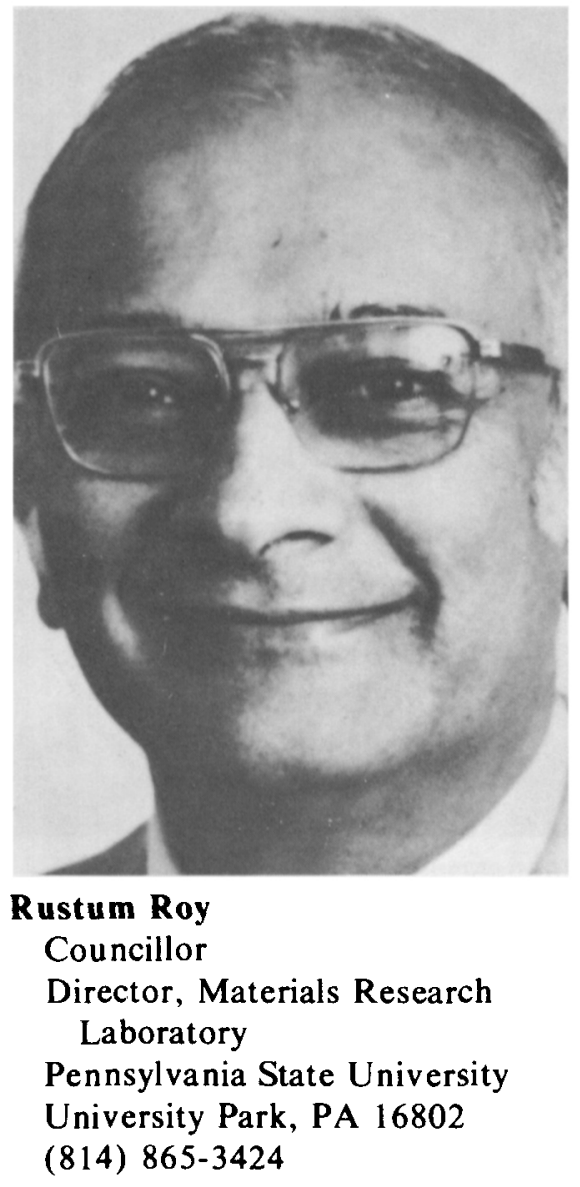

Roy earned his bachelor's and masters degrees in chemistry from Patna University and his Ph.D. in ceramics from Penn State in 1948. After service in his native India, he returned to Penn State, where he is presently Evan Pugh Professor of the Solid State, Professor of Geochemistry, and Chairman of the Science, Technology, and Society Program, in addition to his responsibilities with the materials research laboratory.

Author of some 350 technical papers and several books, Roy's research activities include materials preparation and characterization; crystal chemistry, synthesis, stability, phase equilibria, and crystal growth in non-metallic systems; ultrahigh pressure reactions in solids; and chemistry and physics of noncrystalline solids.

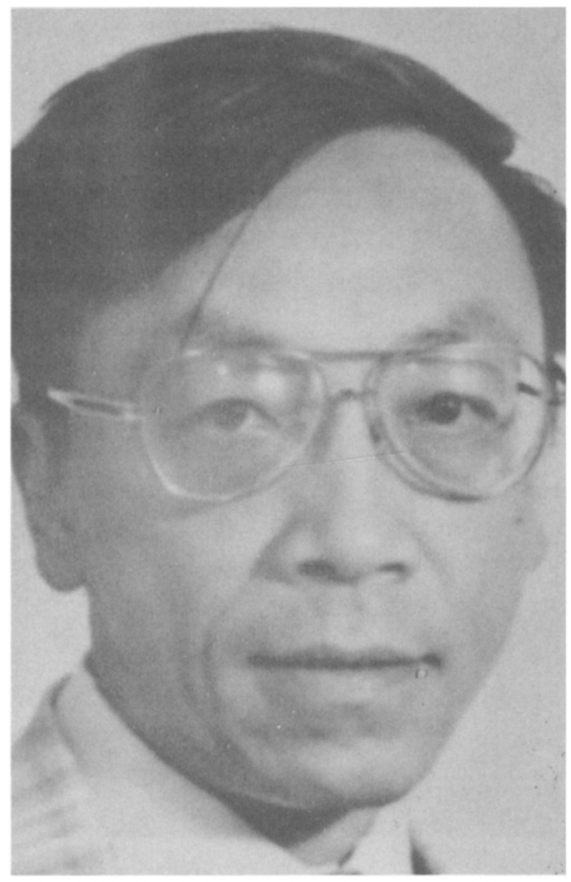

\section{Leroy L. Chang}

Councillor

IBM Research Center

Yorktown Heights, NY 10598

(914) 945-2254

Chang joined IBM's research department in 1963, after taking his $\mathrm{Ph} . \mathrm{D}$. in electrical engineering from Stanford. He has served as an associate professor at MIT and as a member of the National Academy of Sciences' solid state physics delegation to the People's Republic of China.

Since 1975 Chang has been manager of semiconductor microstructures for IBM. His research has involved materials, physics and devices of semiconductors; diffusion, tunneling spectroscopy, field effect and interface properties; and materials aspects of epitaxial deposition and physics aspects of electronic properties. He first synthesized and demonstrated the formation of semiconductor superlattice by molecular beam epitaxy.

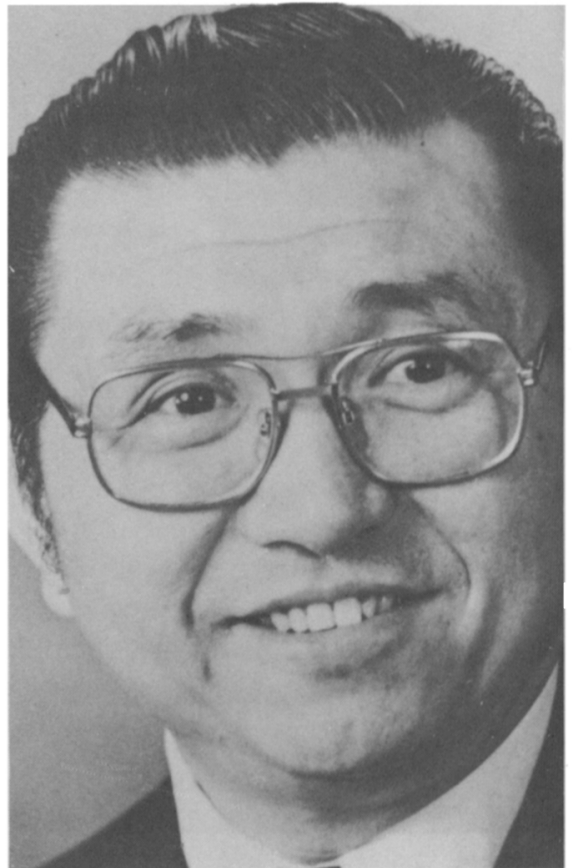

Franklin F.Y. Wang

Councillor

State University of New York

Stony Brook, NY 11794

(516) 246-5980

Wang is professor of engineering and former chairman of the department of materials science at Stony Brook, which he joined after extensive industrial experience with A.O. Smith Corp. and one of its subsidiaries, and with Sperry Rand Corp. His Ph. D. in ceramics is from the University of Illinois, and his other degrees from Pomona College and the University of Toledo.

Editor of the new MRS-affiliated journal, Materials Letters, Wang is interested in semiconductor materials and processing, defects in silicon, polycrystalline silicon and microstructurals in electronic ceramics. Active in professional affairs, he is a fellow of the American Institute of Chemists and the American Ceramic Society. 